\title{
Fichte: del Yo puro al saber absoluto (1798-1802)
}

\author{
Fichte: from pure I to absolute Knowledge (1798-1802)
}

\author{
JACINTO RIVERA DE ROSALES \\ UNED (España)
}

\author{
Recibido: 01-04-2014 Aceptado definitivamente: 21-04-2014
}

\begin{abstract}
RESUMEN
El artículo quiere exponer el cambio que se produce en el pensamiento de Fichte entre 1800 y 1801, que marca la frontera del primer y el segundo Fichte. El principio de su filosofía pasa de ser el Yo absoluto a ser el Absoluto y el saber absoluto. Esto ocurre así a consecuencia de la polémica del ateísmo, de la acusación de nihilismo por parte de Jacobi, y del uso que Schelling hacía del Absoluto en su nueva filosofía de la identidad. Se explica además cómo sucede ese cambio internamente en la Doctrina de la Ciencia, a partir de su síntesis final del mundo de los seres racionales o teoría de la relación interpersonal. Por último se interpreta esa evolución a la luz de la teoría fichteana de los cinco puntos de vista.

PALABRAS CLAVES

FICHTE, ABSOLUTO, POLÉMICA DEL ATEÍSMO, JACOBI, SCHELLING

ABSTRACT

The article aims to explain the change that occurs in Fichte's thought between 1800 and 1801, which marks the border between the first and second Fichte. The principle of his philosophy was the absolute I, and now is the Absolute and the absolute knowledge. This occurs as a result of the controversy of atheism, the charge of nihilism by Jacobi, and Schelling's use of the Absolute in his new philosophy of identity. It is also explained how this change happens internally in the Doctrine of Science, from the final synthesis of the world of rational beings or theory of interpersonal relationship. Finally these developments are interpreted in the light of Fichte's theory of the five points of view.
\end{abstract}




\section{KEY WORDS \\ FICHTE, ABSOLUTE, CONTROVERSY OF ATHEISM, JACOBI, SCHELLING}

\section{EL CAMBIO EN EL HORIZONTE DEL PENSAR}

EN SU PRIMERA ETAPA (1794-1800) FICHTE fundaba su filosofía en el Yo. Este consistía en una autoposición real e ideal, en una acción real que sabe de sí y que Fichte denominaba «intuición intelectual», como lo podemos ver en el $\S 1$ de su WLnm (Doctrina de la Ciencia nova methodo). Esa acción o «agilidad» (no substancia o «cosa» que piensa) encuentra una resistencia que por tanto se denomina No-Yo y que en la Fundamentación de toda la Doctrina de la Ciencia (1794-5) figura como segundo principio del sistema. Es segundo debido a que en parte no es absoluto, sino que su contenido debe ser transformado según las exigencias racionales del Yo puro, y por tanto debe convertirse en dependiente de éste. Pero a pesar de todo se presenta como un principio porque en parte es absoluto y no dependiente del Yo, en el sentido de que no puede ser creado ex nihilo por el Yo, sino que le viene dado. Su resistencia y los límites que impone al Yo son reales, aunque el Yo ha de ponerlos y elaborarlos idealmente desde sí para enterarse de ello: «por consiguiente el Yo es el fundamento de la realidad del No-Yo no de otra manera a como él es el fundamento de la determinación en sí mismo, de la determinación de su pasividad (Leiden): él es meramente fundamento ideal (Ideal-Grund)». ${ }^{1}$ Toda la configuración del saber, dado que éste es actividad ideal, procede del Yo, pero en la acción real el Yo no lo es todo, no es un hen kai pan como la Substancia en Spinoza o la Idea en Hegel, sino que en la realidad se encuentra con el límite real del No-Yo. ${ }^{2}$

Por tanto el Yo puro es llamado «absoluto» por Fichte ${ }^{3}$ no en el sentido de que sea todas las cosas, sino porque no está determinado por nada superior, porque su realidad-acción no es efecto de otra cosa ni tiene su fundamento en otra cosa, sino que es acción originaria, al igual que la libertad en Kant, a partir de la cual ha de ser entendido. En ese plano no hay nada que se le oponga o que le limite, nada que esté por encima o a su mismo nivel o rango con lo que deba compartir la orientación de su acción. Él es el inicio y el sentido de toda la realidad y del sistema completo, alfa y omega. Los juicios téticos que de él proceden son mandatos, tareas a realizar categóricamente e indicaciones que no tienen

1 GWL (Fundamentación de toda la Doctrina de la ciencia), § 4, GA I/2, 325 (= Fichte, Gesamtausgabe, Frommann, Stuttgart, Serie I, tomo 2, página 325).

2 «Todo en su idealidad es dependiente del Yo, pero en relación con la realidad el mismo mismo es dependiente; pero nada es real para el Yo sin ser asimismo ideal [pues en caso contrario no tendría noticia de ello]; por consiguiente en él fundamento ideal y fundamento real son una y la misma cosa, y aquella relación recíproca (Wechselwirkung) entre el Yo y el No-Yo es a la vez una relación recíproca consigo mismo» (GWL § 5, GA I/2, 412).

3 Véase por ejemplo GWL, GA I/2, 271, 279, 282, 386 ss., 396-7, etc. 
rival, por ejemplo, que se amplíe el conocimiento, que se realice la justicia y la libertad, que halla belleza, etc. El No-Yo opone resistencia únicamente a la realización de esas exigencias propias del modo de ser del Yo, pero no lo hace con ese mismo derecho, sino en un nivel inferior, subordinado, como resistencia a la que vencer y como puro medio y lugar de realización. Ambos, Yo y No-Yo, no están englobados «en un concepto superior», sino en uno inferior, en el del tercer principio, en el ámbito de lo divisible (Teilbarkeit). ${ }^{4}$ Por consiguiente tenemos dos niveles o momentos del Yo, uno en el que nada se le opone y es absoluto (tesis), y otro en el que se le opone el No-Yo (antítesis) y tiene que com-partir con él la realidad como yo y no-yo finitos, limitados (síntesis). Podríamos decir que el Yo absoluto de Fichte en Jena es toda la Realität, realidad como categoría de cualidad, pero no toda la Wirklichkeit o realidad efectiva o mundo (categoría de modalidad). Por consiguiente, la contraposición entre el Yo y el No-Yo es a la vez una contradicción dinámica e interna al Yo mismo entre sus dos niveles o momentos señalados. Esto introduce en él una tensión entre la necesaria identificación del Yo consigo mismo y su fáctica dualidad, entre su realidad absoluta, como autoposición y exigencia de libertad, y su realidad efectiva finita. Esta tensión dinámica es la que construye el sistema y le lleva a la acción real transformadora. Esos dos momentos del yo lo encontramos igualmente en Kant como apercepción transcendental y libertad por un lado, y como yo fenoménico o subjetividad empírica y determinada por el otro. Esta dualidad se introduce en el Yo necesariamente porque él, para ser un Yo, necesita saber de sí, y para saber de sí se debe contraponer a lo otro de sí, al No-Yo, pues saber requiere distinción y saber de algo, presupone saber que ese algo no es otra cosa. Por eso le surge el mundo y su propia finitud, sin la cual no habría conciencia ni Yo. Esa contraposición entre originariedad subjetiva y finitud es lo propio de la reflexión o método transcendental.

Pues bien, a partir de la WL01/02 (= Doctrina de la ciencia de 1801/1802) Fichte plantea su filosofía en términos algo diferentes. Como veremos, el motivo histórico de este cambio es la acusación que se lanzó contra él de ateísmo a finales de 1798, y por la que perdió en 1799 su cátedra en la Universidad de Jena. Aunque hay elementos que continúan estando presentes, el horizonte de su filosofia se modifica. Para visualizarlo hay que fijarse en dos puntos decisivos: la aparición del Absoluto y la desaparición del No-Yo. Ahora Fichte afirma que existe el o lo Absoluto y el saber, y que «el saber no es el Absoluto, pero en cuanto saber él mismo es absoluto», 5 con lo cual quedaría el No-Yo como mero momento del desarrollo de ese saber absoluto. Podríamos decir que el Yo absoluto de Jena se desdobla en un Absoluto real que no es saber ni intuición intelectual, y en un saber que no es el Absoluto sino su manifestación, pero que englo-

4 GWL § 3, GA I/2, 279.

5 WL01/02 (= Doctrina de la ciencia de 1801-1802), GA II/6, 153. 
ba dentro de sí toda la realidad que conocemos y en ese sentido es absoluto. Ese saber debe llegar a comprender que él no es el Absoluto real mismo, sino su imagen, su existencia, su manifestación, su luz exterior, y de esa manera indirecta, mediante sl despliegue sistemático del saber, el Absoluto mismo se revela. Esta es la tarea de la WL.

Este artículo pretende mostrar que entre 1800 y 1801 se produce en Fichte un cambio en el horizonte del pensar. Esto nos proporcionará una comprensión global de ambos períodos. Nos moveremos entre 1798 y 1802.

\section{JACOBI Y EL NIHILISMO}

Detrás de ese nuevo enfoque de la filosofía de Fichte se encuentra una clara influencia de Jacobi, cada vez más estudiada. En la conocida carta abierta que Jacobi escribe a Fichte en marzo de 1799 en el marco de la polémica sobre el ateísmo, Fichte fue acusado de nihilismo. Jacobi piensa que no es la razón especulativa sino la fe la que puede alcanzar y captar la realidad en general, y en particular la existencia de lo Infinito o de Dios. Por eso proclama su «nofilosofía (Unphilosophie), que tiene su esencia en el no-saber», ${ }^{6}$ y condena la filosofía racional de Spinoza y de Fichte. Estos pretenden fundar su filosofía en el saber desembocando en el ateísmo. Además la filosofía de Fichte parte de un subjetivismo que se queda en la mera forma del saber.

Spinoza y Fichte caminan hacia la misma meta, aunque por caminos opuestos, afirma Jacobi. En esto retoma una idea que Schelling expuso en la novena de sus Cartas filosóficas sobre el dogmatismo y el criticismo. Ambos sistemas señalados, sostiene el joven Schelling, se dirigen hacia un mismo propósito, hacia la identidad absoluta de sujeto y objeto, y por tanto hacia la desaparición de toda escisión y con ella de uno mismo, aunque por caminos opuestos. El dogmatismo quiere que el sujeto se identifique con el objeto absoluto a través de la sumisión, mientras que el criticismo va hacia la absoluta identidad del sujeto por medio de su libertad.

Pero «una actividad ilimitada es igual que un reposo absoluto», ${ }^{7}$ dado que en lo Absoluto no es posible ninguna limitación ni diferencia, y por tanto tampoco ninguna conciencia. Un realismo pleno coincide con un idealismo llevado hasta el final. «Dogmatismo y criticismo sólo pueden afirmarse como sistemas contrarios en su acercamiento al objetivo final», ${ }^{8}$ cuando están en el camino, pero no ya en su objetivo logrado. Sin embargo ninguno de ellos consigue alcanzar lo Absoluto desde el saber, en el ámbito de lo teórico, porque en el saber siempre se da una separación y una diferencia entre sujeto y objeto. Por consiguiente, lo Absoluto ha de ser objeto de la acción. El dogmatismo debe anular toda causali-

6 GA III/3, 226, 1.

7 AA I/3, 96 (Cotta I, 327).

8 AA I/3, 102 (Cotta I, 331).

Suplemento 19 (2014) de Contrastes. Revista internacional de filosofía 
dad libre en nosotros y dejar únicamente el actuar objetivo. El idealismo debe realizar lo Absoluto en nosotros mismos mediante una infinita aspiración hacia la mismidad, mediante la libertad incondicionada y la actividad ilimitada. ${ }^{9}$ Jacobi retoma esa idea de Schelling y califica al idealismo de Fichte de «spinozismo invertido» y de «materialismo sin materia». ${ }^{10}$

Jacobi sostiene que Fichte no puede captar la realidad (nihilismo), o sea, lo verdadero y menos aún la existencia de Dios (ateísmo) por medio del saber y de sus conceptos, pues lo verdadero se halla fuera del saber y de su verdad. «Mediante la razón no le es concedida al hombre la facultad de una ciencia de lo verdadero, sino únicamente el sentimiento y la conciencia de su no-ciencia sobre ello: un presentimiento de lo verdadero». ${ }^{11}$ Eso verdadero es lo que otorga valor a la razón. «Donde falta la indicación hacia lo verdadero, allí no hay ninguna razón. Esta indicación, la necesidad de considerar lo verdadero, que únicamente se le presenta en el presentimiento, como su objeto, como el último propósito de todo deseo de conocer, constituye la esencia de la razón. Ella se dirige exclusivamente a lo escondido detrás de los fenómenos y a su significado, al ser que sólo ofrece una apariencia de sí y que ha de transparentarse en los fenómenos si es que esos no-fantasmas-en-sí no deben ser fenómenos de nada». ${ }^{12}$ (Podemos constatar que el segundo Fichte toma ese camino a su manera, sin aceptar el teísmo de Jacobi: lo verdadero de Jacobi es el Absoluto de Fichte, la razón y el fenómeno es el saber, y la indicación o aquello que señala hacia el Absoluto es el saber del saber, o sea, la Doctrina de la Ciencia). Jacobi estima que Fichte ha llegado más lejos que Spinoza: «Una filosofía pura, esto es, totalmente inmanente, $[\ldots]$ un verdadero sistema de la razón, sólo es posible a la manera de Fichte. Evidentemente todo tiene que ser dado exclusivamente en la razón y por ella, en el Yo en cuanto Yo, en la yoidad». ${ }^{13}$ Jacobi sostiene que la razón pura sólo se percibe a sí misma, todo lo que está fuera de ella se convierte en nada. La conceptualización transforma a las cosas en meras figuras, en esquemas que nosotros construimos, pero toma esas figuras por cosas y de ese modo trueca las cosas en nada. Así es la ciencia, una acción que disuelve toda esencia en el saber, en donde no se encuentra realidad alguna. El idealismo fichteano es como una media sin pierna, nada más que un vacío tejer por parte del saber, que no contiene ninguna realidad.

Contra esta crítica de Jacobi Fichte quiere mostrar en sus posteriores exposiciones de la WL, primero, que su filosofía se funda en la verdadera realidad, es decir, en el Absoluto y no es un nihilismo, y segundo, que él, de una manera

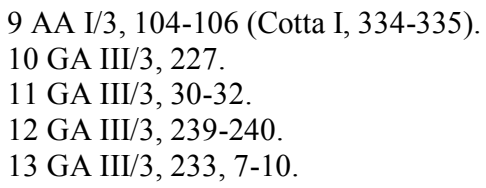


crítica y enteramente transcendental, establece asimismo una diferencia entre el Absoluto y el saber.

En primer lugar, el segundo Fichte entiende y expone su afirmación del Absoluto o del Ser absoluto o Dios como su realismo radical contra toda acusación de nihilismo. Esta idea la encontramos por ejemplo en la WL11: «Hay Ser. [...] La WL lo sabe absolutamente, y lo acepta previamente a todo lo demás, y por eso es propiamente y en su raíz un realismo. Ningún sistema filosófico [...] acepta esto con toda seriedad [...] Ellos [los otros sistemas] quieren obtener el Ser mediante el pensar, por medio de un razonamiento, a consecuencia de una premisa [...]. Todos ellos son idealistas [... Pero nuestra WL afirma] que Él es en sí, desde sí y por sí lo que es y puede ser, y ese «por sí» es su ser; es por tanto un ser interno y vivo, todo ser, y fuera de él no puede haber ser alguno. Dios, y fuera de él nada». ${ }^{14}$ En la $W L 04^{2}$ Fichte manifiesta su predilección por la visión realista en el ascenso hacia el punto supremo del sistema, ${ }^{15}$ porque además ella permite a su lado la visión idealista en el descenso, o sea, en la construcción del sistema propiamente dicho, en la doctrina del fenómeno o construcción del mundo, tanto material como humano. Por el contrario, si se adoptara la visión idealista como la más elevada, ella destruiría toda visión realista, lo cual manifiesta la unilateralidad que se cometería en ese caso.

Ahora bien, el realismo nos conduce hacia un Ser incomprensible (unbegreiflich), que no puede ser captado por medio de conceptos, y por tanto no nos sirve como principio de una WL, en donde todo ha de ser comprendido (begriffen) genéticamente. ${ }^{16}$ El Ser absoluto, que en realidad podríamos entender como un Ente absoluto, es la ratio essendi del saber, pero son el saber y su saber-se (trasunto de la auto-conciencia del Yo) la ratio cognoscendi del saber mismo. En consecuencia la WL no es ni puede ser una doctrina sobre el Ser (o Ente) absoluto, sino una doctrina sobre el saber, un saber absoluto que es nuestro nuevo hen kei pan. El Ser como tal se manifiesta únicamente cuando el saber se comprende como mero saber, o sea, como no teniendo un ser propio, sino siendo imagen del Ser. Esto es lo que se barrunta en la moral superior, se percibe bastante en la visión religiosa, y plenamente gracias a la WL; de ahí la importancia y la necesidad de la WL. En ella poco se dice sobre el Ser absoluto, pues la realidad de éste se sitúa fuera del saber, únicamente que es por sí y desde sí, lo que Fichte conceptúa como vida originaria, por cuanto que no es producto de otra cosa. Cualquier otro término que se le quiera añadir al Absoluto quebraría su carácter de absoluto y le pondría en alguna relación. ${ }^{17}$

14 WL07, GA II/10, 165-166.

$15 \mathrm{GA} \mathrm{II} / 8,172$ y 264.

16 GA II/ $/ 8,172,18-20$.

17 WL01/02, GA II/6, 143-144. 
En segundo lugar, Fichte está de acuerdo con Jacobi cuando éste rechaza que el saber pudiera captar lo Absoluto o absolutamente real. Pero Fichte entiende ahora el saber de otra manera a como lo hace Jacobi y a como lo hizo él mismo en su etapa jenense, con un radio de acción y un alcance mucho más amplio, a saber, no como una acción meramente subjetiva, del sujeto humano, sino como una acción a partir de la cual se deduce toda la realidad de nuestro mundo: él es

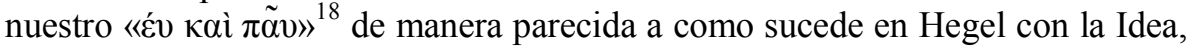
pues también a partir de ella y de su proceso de autoconocimiento se genera todo nuestro mundo. «El saber no es el Absoluto, pero él en cuanto saber es absoluto». ${ }^{19}$ Aparte del Absoluto sólo se da el saber; él es la única posible y eterna manifestación del Absoluto, ${ }^{20}$ porque sólo la acción de saber puede saber de sí y además es sólo imagen, forma pura, sin un ser propio que pudiera hacerle la competencia al Absoluto y ponerle límites. Por consiguiente Fichte establece también una diferencia ontológica entre el Absoluto y el saber, la que hay entre el Ser y su imagen, de modo que el saber sólo alcanza a tener un concepto del Absoluto y no al Absoluto mismo. El error de Spinoza es no haber reflexionado sobre su propio pensar y creer por tanto que tenía al Absoluto mismo en su pensar. ${ }^{21}$ Esta misma acusación se la lanzará a Schelling. Gracias a esa reflexión crítica del saber sobre sí mismo y a la consiguiente autolimitación ontológica del saber, Fichte afirma que él sigue fiel al modo de pensar transcendental, pues no confunde el Ser con el pensar. ${ }^{22}$ Es en la WL donde el saber se comprende plenamente a sí mismo como mera imagen, se anula (sich vernichtet), es decir, se niega a sí mismo el tener un ser en sí propio, y en ese mismo acto se realiza como manifestación o conciencia del Ser absoluto en cuanto lo otro del saber. El Yo de Jena, como intuición intelectual, queda por tanto del lado del saber: nosotros somos sólo saber, esquema, imagen hasta en nuestra raíz. ${ }^{23}$ «Lo que él [Spinoza] [piensa] del Absoluto, lo [pensamos] nosotros también de su fenómeno [o manifestación. ...] El verdadero paralelo [con Spinoza]. Uno y todo lo mismo. Év кaì $\pi \tilde{\alpha} v$. Todo en el Uno, todo Uno. En efecto, a saber, en el único fenómeno. En Él [Dios] vivimos, nos movemos y somos: ciertamente, en su fenómeno, nunca en su ser absoluto». ${ }^{24}$ Estamos en Dios en la medida en que podemos

18 WL12, GA II/13, 60.

$19 \mathrm{GA} \mathrm{III} / 5,112-113$.

20 «Me parece en sí claro que el Absoluto sólo puede tener una manifestación absoluta, es decir, en relación a la multiplicidad enteramente una sola, simple y eternamente igual a sí misma; y esta es justamente el saber absoluto» (Carta de Fichte a Schelling del 15 de enero de 1802; GA III/5, 112-113).

21 WL12, GA II/13, 52 y 60.

22 WL042, GA II/8, 344-6. WL07, GA II/10, 185. WL12, GA II/13, 52 y 68. WL13, SW

X, 4 (anotación del hijo de Fichte).

23 WL10, GA II/11, 345, 350, 351, 364.

$24 \mathrm{WL} 12, \mathrm{GA}$ II/13, 60. 
estar, o sea, en su fenómeno o manifestación. No estamos en (in) Dios, como cree Spinoza, sino junto a (an) Dios. ${ }^{25}$

\section{SCHELLING Y EL ABSOLUTO}

Además de Jacobi, otro elemento que influye en el cambio que experimenta Fichte en su horizonte del pensar es Schelling. En la Introducción a sus Ideas para una filosofía de la naturaleza (1797), Schelling había afirmado, contra la concepción fichteana de la naturaleza, que nosotros no transferimos el concepto a los seres vivos, sino que el ser vivo contiene ya en sí mismo el concepto y es éste el que lo organiza como un todo, el que da sentido y función desde su totalidad a las partes del ser vivo. Este se produce a sí mismo pues lleva en sí el fundamento de su existencia como organización, el cual no le viene de fuera como le ocurre al artefacto. ${ }^{26}$ Quien no piensa así la naturaleza viva, y eso es lo que ocurre en la mera filosofía de la reflexión (o sea, en Fichte), destruye toda idea de la naturaleza, ${ }^{27}$ pues lo que aparece a la luz en la naturaleza orgánica nos proporciona la correcta visión de lo que es la naturaleza en su esencia, a saber, «una unión originaria de espíritu y materia [...]. Aquí sobrevino por primera vez al hombre el barrunto de su propia naturaleza, en la cual intuición y concepto, forma y objeto, ideal y real son originariamente uno y lo mismo». ${ }^{28}$ En consecuencia existe una continuidad entre la naturaleza y el hombre, aunque también una diferencia de grado o «potencia» de la actividad ideal configuradora, lo que nos pone en el camino hacia el Absoluto del que surgen ambos. Schelling puede anunciar en su Primer esbozo de un sistema de la filosofía de la naturaleza (1799): «El filósofo de la naturaleza trata a la naturaleza del mismo modo que el filósofo transcendental [Fichte] trata el Yo»». ${ }^{29}$ La naturaleza no es sólo objeto, sino sujeto-objeto. Pero los fundamentos de esa originaria subjetividad de la naturaleza Fichte no los percibió con claridad en su lectura del Sistema del Idealismo transcendental (1800) de Schelling, y rechazó la filosofía de la naturaleza de Schelling tachándola de dogmatismo.

$\mathrm{Al}$ inicio de la «Introducción»al Esbozo (1799) explica Schelling que la inteligencia o actividad ideal (estamos en un sistema idealista) puede actuar ciegamente, sin conciencia, y entonces su producto es la naturaleza, en donde encontramos una identificación de la actividad productora (natura naturans, naturale-

25 WL10, GA II/11, 345, 350, 351, 364. WL11, GA II/12, 274, 1. 6. WL12 GA II/13, 96. $\mathrm{ThB}, \mathrm{GA}$ II/ $15,40,55,124$.

26 Schelling AA I/5, 94 (Cotta II, 41).

27 AA, I/5, 98-100 (Cotta II, 45 y 47).

28 AA, I/5, 99-100 (Cotta II, 47).

$29 \mathrm{AAI} / 7,275$ (Cotta III, 12 nota).

$30 \mathrm{GA} \mathrm{II} / 5,414$.

Suplemento 19 (2014) de Contrastes. Revista internacional de filosofía 
za como sujeto) y del producto (natura naturata, naturaleza como objeto). ${ }^{31}$ Pero la inteligencia puede llegar a ser productiva también de manera libre y con conciencia, y entonces estamos en el ámbito del Yo fichteano, el de los humanos, donde se da una distinción entre la acción productiva y el producto, entre el carpintero y la mesa, entre el Yo y el No-Yo, distinción que posibilita que la inteligencia se haga consciente de su productividad. En un tercer momento la filosofía supera esa contraposición y muestra que ambas manifestaciones lo son de la misma actividad. Esta unidad básica se objetiva en la obra de arte del genio $^{32}$. Este es el programa del Sistema.

Schelling, en su Sistema del idealismo transcendental (1800) construye el mundo de la naturaleza y del espíritu con las mismas actividades productivas que veíamos en el Yo de Fichte. Pero el Yo schellingiano que así se despliega, dando lugar a la realidad de todo nuestro mundo, ya no es el Yo humano en el

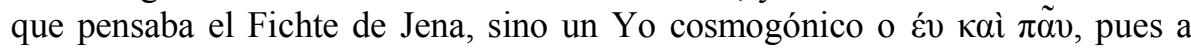
partir de él se crea y surge todo nuestro mundo, tanto la naturaleza como el mundo humano, y no sólo de manera idealiter, sino también materialiter, que es lo que sucederá igualmente con el saber absoluto del segundo Fichte. La construcción real-ideal de todo nuestro mundo se produce en virtud de la potenciación de la actividad ideal. En un primer momento la actividad ideal del Yo (diríamos del Yo cosmogónico) limita su propia actividad real, la cual se convierte en real justamente en virtud de esa limitación. El resultado aquí es el Stoff, que podríamos compararlo con la materia prima aristotélico-escolástica. La actividad ideal, limitante, es y permanece siendo de suyo ilimitada, por tanto puede salir de este primer acto y eso es lo que hace para seguir construyendo al Yo, pues éste no logra aún saber nada de sí en esa su primera acción. En consecuencia, lo primero que la actividad ideal lleva a cabo es poner en sí misma la limitación ya puesta en la actividad real, y con ello se produce en la actividad ideal la sensación o noticia originaria de la limitación. La limitación es entonces sentida pero como ya dada y por tanto el Yo proyecta fuera su origen y la pone como viniendo de un No-Yo, que es el punto de vista dual y fuera del Absoluto en el que se sitúa (el primer) Fichte. Por tanto la propuesta de Schelling es que la limitación de la actividad del Yo es producida por su propia actividad ideal. La filosofía recupera así una actividad del Yo que éste alienaba, el Yo se reconcilia consigo mismo, y descubrimos que todo nuestro mundo es producto del Yo. Esta génesis schellingiana del Yo continúa con sucesivas potenciaciones de la actividad ideal (el sistema es un idealismo) que dan lugar sucesivamente a los objetos inertes, a los vivos, a la libertad y a los diversos momentos del mundo humano. El proceso se concluye en el arte, que objetiva en la obra el punto de partida del filósofo: la unidad de naturaleza y espíritu. De aquí parte el sistema de Hegel, el cual expli-

31 AA I/8, 41 (Cotta III, 284).

32 AA I/8, 29 (Cotta III, 271). 
ca toda la realidad como desarrollo graduado de la Idea, que va desde la exterioridad máxima del espacio-tiempo-materia hasta la interioridad omniabarcante del Espíritu absoluto.

Algo similar sucede en el segundo Fichte con su doctrina del fenómeno (Erscheinungslehre), en la cual domina enteramente el idealismo, pues el surgimiento y explicación del mundo se lleva a cabo a partir del saber absoluto. Este juega en él el papel del $\varepsilon ́ v$ kaì $\pi \tilde{\alpha} v$ de toda nuestra realidad, ${ }^{33}$ pues además del Absoluto sólo está el saber, que la única manifestación posible del mismo. ${ }^{34}$ Pero como no puede haber dos seres absolutos, dado que uno limitaría al otro, el saber no tiene un ser propio, sino que es mera imagen y manifestación del Ser: «El saber es esencialmente y desde su base fenómeno [manifestación, Erscheinung], imagen, esquema: el Ser no aparece en él, sino que permanece pura y simplemente en Dios». ${ }^{35}$ Eso arrastra consigo al mundo y a nosotros, que no somos sino momentos del saber absoluto y su despliegue: «El mundo fáctico es un sistema de imágenes y conceptos, de ciertas determinaciones del ver [o saber] y absolutamente nada más. Este es el idealismo de la WL». ${ }^{36}$ Esta diferencia la marca claramente Fichte incluso en su filosofía de la religión y hablando del amor y de la unión con Dios: «Nosotros somos en nuestra esencia no erradicable sólo saber, imagen y representación [...] Incluso en este nuestro coincidir con Él [con Dios en la bienaventuranza] no deviene Él nuestro propio ser, sino que únicamente está ante nosotros (vorschwebt), como algo distinto (fremdes) y que se encuentra fuera de nosotros, al que exclusivamente nos hemos de entregar y estrechar con íntimo amor». ${ }^{37}$ «Por tanto, la WL opera enteramente dentro del fenómeno [de la manifestación del Ser absoluto] al igual que Spinoza dentro del Ser»». ${ }^{38}$ Pero el despliegue de ese fenómeno del Ser absoluto, o sea, del saber, procede en Fichte primero de arriba hacia abajo, hasta el mundo empírico, y sólo entonces comienza un ascenso por parte del yo hasta la WL, que cierra el círculo del saber. Es un movimiento parecido al del neoplatonismo.

En su Exposición de mi sistema de la filosofía (1801) Schelling se distancia de manera pública por primera vez de Fichte con su filosofía de la identidad. Tomando a Spinoza como modelo, construye su sistema partiendo expresamente del Absoluto. La filosofía de la naturaleza y la filosofía transcendental convergen en un punto de indiferencia anterior a la división. Allí reside la razón absoluta, que es total indiferencia de lo subjetivo y de lo objetivo. Gracias a esa abs-

33 WL12, GA II/13, 60. Véase también Über das Wesen des Gelehrten, GA I/8, 71-72.

34 El saber es «en efecto un accidente de Dios, como en Spinoza, pero sólo Uno» (WL07, GA I/10, 169), sólo cogitatio. Fichte conoce la Ética de Spinoza, pero traduce el término de «atributo» por «accidente».

35 WL11, GA II/12, 157. «... el Ser está separado y escondido en Dios» (o. c., 170, 1. 10).

36 WL12, GA II/13, 127, 14-16.

37 ASL (Exhortación a la vida bienaventurada), GA I/9, 103, 1. 4-9..

$38 \mathrm{WL} 12, \mathrm{GA}$ II/13, 59. 
tracción llegaríamos al verdadero en-sí, en cuya esfera elabora Schelling una especie de teología (a partir de ahí desarrollará Hegel su Ciencia de la lógica). «El punto de vista de la filosofía es el punto de vista de la razón. Su conocimiento es un conocimiento de las cosas como son en sí mismos, es decir, como ellas son en la razón. [...] Fuera de la razón no hay nada y en ella está todo. [...] No hay otra filosofía que la del punto de vista del Absoluto, [...] la razón es lo Absoluto». ${ }^{39}$ A continuación Schelling analiza esa razón absoluta. Ella es absolutamente una e igual a sí misma. Su ley y esencia supremas es la identidad. Es eterna e infinita. Se conoce a sí misma. El principio de identidad es el conocimiento originario de la absoluta identidad. Es totalidad absoluta, no causa del universo, sino el universo mismo. La diferencia, y en concreto la diferencia cuantitativa entre subjetividad y objetividad sólo se da en las cosas individuales, no en la identidad absoluta, y es el fundamento de toda finitud (§ 37). El tratado va hasta la deducción de la naturaleza orgánica.

Fichte comienza entonces, a continuación, a filosofar también desde lo Absoluto. Era el espíritu filosófico de la época. Recibió la Exposición de Schelling en mayo de 1801, y en octubre usa Fichte el término de Absoluto, que antes no había aparecido en su vocabulario. Pero en ello reacciona asimismo contra la concepción que Schelling tiene del Absoluto, decidiéndose en este punto a favor de Jacobi y de la inaccesibilidad conceptual de Dios, del cual nada se puede decir aparte de que es el Absoluto. A causa de Schelling y Jacobi, Fichte tenía asimismo que confrontarse con Spinoza. Esa confrontación le sirve a Fichte incluso de hilo conductor para la presentación de su filosofía en la WL12. ${ }^{40}$ Según él, ni Spinoza ni Schelling han reflexionado críticamente y de una manera transcendental sobre su propio acto de pensar cuando están pensando al Absoluto, y por eso creen que tienen en su mano al Absoluto mismo, cuando en realidad sólo poseen la idea de Él, y la idea no es Dios mismo. Por esa confusión arrastran al Absoluto al devenir y a la multiplicidad o pluralidad de seres, cuando en él no puede haber nada de eso. Hay por consiguiente que destruir ese concepto habitual del Ser absoluto. ${ }^{41}$ Hemos de distinguir el Absoluto y el saber, como deseaba Jacobi, y presentar al Absoluto como estando fuera del saber, como lo no comprensible o captable mediante conceptos (unbegreiflich). Justamente porque la WL permanece en el saber y no es doctrina del Ser, sino que, al contrario que Spinoza y en continuidad con Kant, distingue entre ser y concepto, ella sigue siendo para Fichte un idealismo transcendental. ${ }^{42}$ En una carta a Schad del 29 de diciembre de 1801 escribe Fichte: Mi nueva exposición «mostrará que

$39 \S \S 1$ y 2 , Cotta IV, 115.

$40 \mathrm{GA} \mathrm{II} / 13,51$ ss.

$41 \mathrm{WL} 01 / 02$, GA II/6, 130-131.

42 Carta a Schelling 15.1.1802 (GA III/5, 112). WL042, GA II/8, 344-6. WL07, GA II/10, 185. WL12, GA II/13, 52 y 68. WL13, SW X, 4 (anotación del hijo de Fichte). 
el Absoluto (al cual justamente por eso, por ser el Absoluto, no se le puede añadir ningún predicado, ni el del saber ni el del ser, ${ }^{43}$ ni tampoco el de la indiferencia entre ambos ${ }^{44}$ ) ha de ser puesto en el fundamento; que Él se manifiesta en sí mismo como razón, se cuantifica, se divide en saber y ser [en sujeto y objeto] y ya en esa figura desemboca en una identidad del saber y del ser infinitamente diversa». ${ }^{45}$ En la primera lección de la WL $1804^{2}$ Fichte sostiene algo que no encontramos ni en Kant ni en el Fichte de Jena: «La tarea de la filosofia puede ser expresada así: exposición del Absoluto» ${ }^{46}$ ya sabemos, exposición del saber absoluto, no del Ser absoluto mismo, que está más allá de todo saber.

Claramente no era ese aún el propósito de Fichte cuando escribió la carta a Schelling del 15 de noviembre de 1800, reaccionando ante el Sistema del idealismo transcendental: «Pienso que ni la cosa [el objeto] se añade a la conciencia, ni la conciencia a la cosa, sino que ambos están inmediatamente unidos en el Yo, en el Yo ideal-real, real-ideal. Algo diferente ocurre con la realidad de la naturaleza. Esta última aparece en la filosofía transcendental como algo enteramente encontrado, y además como algo acabado y concluso; pero encontrado no según leyes propias, sino según leyes inmanentes de la inteligencia (como idealreal)», ${ }^{47}$ al igual que en Kant. Así es la naturaleza para una inteligencia finita. ¿Pero sería ella algo encontrado también para el saber absoluto, cuando sólo ese saber existe además del Absoluto y no hay lugar para haya junto a ellos una naturaleza encontrada? El mismo horizonte o punto de vista adopta Fichte en su carta a Schelling del 7 de diciembre de 1800 . Él piensa que a su filosofía «le falta aún un sistema transcendental del mundo inteligible», ${ }^{48}$ el desarrollo del mundo de los seres racionales, con el cual sin embargo había concluido su WLnm y el libro El destino del hombre (1800). Pero ahora esa parte está pensada como «una nueva prolongación o extensión de la filosofía transcendental, incluso en sus principios» ${ }^{49}$ (Schelling se puso contento con esa afirmación ${ }^{50}$ ), una extensión que Fichte deja sin aclarar en la carta, pero que ya apunta a su segundo período, pues eso es lo que terminará ocurriendo. Pero él mientras tanto se desdice de esta observación en su siguiente carta a Schelling del 31 de mayo / 7 de agosto de 1801, mostrando así las oscilaciones de su pensamiento anteriores

$43 \mathrm{O}$ sea, no se puede decir que el Absoluto sea ni sujeto ni objeto. Téngase se cuenta que en Fichte el término «ser» tiene también el significado de objeto o cosa, y ese fue además el significado que primeramente tuvo en su sistema.

44 Esta es la crítica que ahora hace Fichte a la nueva concepción que Schelling tiene del Absoluto en su llamada filosofía de la identidad.

$45 \mathrm{GA} \mathrm{III/5,} 102$.

46 WL042, GA II/8, 10.

$47 \mathrm{GA} \mathrm{III} / 4,360,19-25$.

$48 \mathrm{GA} \mathrm{III} / 4,406,21-22$.

$49 \mathrm{GA}$ III/4, 406, 15.

$50 \mathrm{GA}$ III/ $/ 5$ 83-84.

Suplemento 19 (2014) de Contrastes. Revista internacional de filosofía 
al salto hacia el nuevo horizonte: «A la WL no le falta nada en sus principios, pero sí ciertamente en su conclusión; la síntesis suprema no está en efecto realizada, la síntesis del mundo de los espíritus. Cuando me disponía a elaborar esta síntesis gritaron justamente «ateísmo»»». ${ }^{51}$ De nuevo aquí Fichte liga a Dios con esa síntesis suprema y final del sistema, de modo parecido a lo que ocurría en Kant con su concepto de «reino de Dios». ${ }^{52}$ Por «mundo de los espíritus» Fichte entiende en esta carta una conciencia universal que sería el fundamento de la evidencia de la conciencia individual, la última y suprema síntesis de los individuos racionales, «fundamento-real de la separación de los individuos, vínculo ideal de todos $=$ Dios $[\ldots]$ total agilidad, pura transparencia, luz [...]. Cada individuo es una visión particular de ese sistema [del mundo de los espíritus] desde un punto propio y fundamental», ${ }^{53}$ mientras que la WL logra penetrar esa conciencia universal. La naturaleza por su parte ha de «ser deducida mediante las leyes de la razón finita». ${ }^{54}$ Fichte sigue estando pues en el horizonte de la finitud de su período de Jena.

Como hemos visto, él habla por primera vez del Absoluto en su carta a Schelling de octubre de 1801. En una carta anterior, la del 3 de octubre de 1801, Schelling le había explicado su idea de que el Absoluto es identidad del pensar y del intuir, de fundamento ideal y real, de lo finito y de lo infinito, al ser absoluta indiferencia o ser supremo, que en consecuencia no tiene contrario. No se podría por tanto pensar ese primer principio como lo hace Fichte, como pura agilidad, puesto que una absoluta actividad es igual que un absoluto reposo; el Absoluto es, pero no es activo. «Este Absoluto, digo en mi Exposición, existe en la forma de la diferencia cuantitativa (esto es la intuición, que siempre es una determinada) en lo singular, y en la forma de la indiferencia cuantitativa (eso es el pensar) en el todo».$^{55}$ Esto sería para Fichte la síntesis del mundo de los espíritus, añade Schelling, la última síntesis del sistema. Pero si ella es la síntesis suprema, ha de ser a la vez lo primero, el principio del filosofar (el sistema filosófico forma un círculo). Entonces la filosofía tiene que tomar la dirección contraria, pues ha de ir desde arriba hacia abajo. Tiene que declarar como algo provisional el principio de Fichte (el Yo puro) y como propedéutica su filosofía, porque en ella el principio supremo (la síntesis suprema) aparece como un resultado y miembro final. La verdadera especulación ha de comenzar, por el contrario, con el Absoluto, con lo verdadera y originariamente real, no con el ver o saber, no «como en

$51 \mathrm{GA}$ III/5, 45, 10-13.

52 Religion, AA VI, 134; Streit, AA, VII, 68, 74. «El reino de Dios sobre la tierra: ese es el último destino del hombre» (Kant, Reflexión 1396; AA XV, 608).

53 GA III/5, 48, 12-13, 16-17, 24-25.

$54 \mathrm{GA} \mathrm{III/} / 5,49,9$.

$55 \mathrm{GA}$ III/5, 81, 27-30. 
la filosofía kantiana, en donde primero ha de venir la ley moral y al final Dios». ${ }^{56}$

En su respuesta de octubre de 1801a esta carta de Schelling Fichte acepta y utiliza por primera vez el concepto de Absoluto, «sobre el cual y sobre cuya determinación estoy enteramente de acuerdo con Usted, y también poseo la intuición del mismo desde hace mucho tiempo ${ }^{57}$. ¿Se refiere a su concepto del Yo puro? Pero éste se encontraba con la naturaleza, con el No-Yo, mientras que el Absoluto de Schelling crea desde sí ese No-Yo o naturaleza. En todo caso Fichte le declara en esa carta que el Absoluto no puede existir en la forma de la diferencia cuantitativa. «El Absoluto no sería el Absoluto si existiera bajo alguna forma». ${ }^{58}$ Lo que Fichte no puede aceptar es que se mezcle al Absoluto con lo finito en ningún momento ni en ningún respecto. La última carta de Schelling a Fichte se ha perdido, pero no la de Fichte a Schelling del 15 de enero de 1802. En ella se queja de que Schelling en su cátedra se burle de él y de su punto de vista, como siendo el de la mera reflexión, en el que él se habría quedado. Schelling piensa así, prosigue Fichte, porque no se ha alzado a la reflexión fundamental y no ha reflexionado sobre su propio pensar. A consecuencia de ello deja que entre en el Absoluto la forma de la finitud y del saber. Su Absoluto por tanto es una identidad negativa, una no-distinción del saber y del ser, o sea, una composición que presupone una separación del saber relativo y del ser relativo (del Yo y del No-Yo relativos), luego ningún verdadero Absoluto, sino la idea del Absoluto en el ver, en el saber, el cual requiere siempre una duplicidad. Inmediatamente después Fichte redactó su WL01/02, donde ya pone en juego al Absoluto como realidad suprema, y junto a él al saber absoluto como su única manifestación.

\section{LO DIVINO QUE GOBIERNA EL MUNDO}

Hemos visto sobre todo la cara externa del cambio que se produce en Fichte hacia 1801. Ahora hemos de adentrarnos directamente en su cara interna y ver desde dónde surge ese Absoluto en el interior de la Doctrina de la ciencia, o sea, estudiar el desarrollo de esa síntesis de los seres racionales. Este cambio comienza con el eco que tuvo su artículo «Sobre el fundamento de nuestra fe en un gobierno divino del mundo» (1798). ${ }^{59}$ Fue el primer escrito que Fichte publicó sobre filosofia de la religión (si no tenemos en cuenta su Ensayo de una crítica de toda revelación (1792), pues él no había descubierto aún su propia filosofía),

56 GA III/5, 82, 28-29.

57 GA III/5, 91, 2-3.

$58 \mathrm{GA} \mathrm{III/5,91,9-10.}$

59 Véase su traducción en el libro La polémica sobre el ateísmo, Dykinson, Madrid, 2009, pp. 137-147. En ese volumen colectivo se recogen las traducciones de otros textos importantes en esa polémica y artículos sobre ese asunto. 
aunque muchas ideas del artículo ya se encontraban en su Etica, la que acababa de aparecer ese mismo año, por ejemplo en el § 30. La publicación del artículo provocó la polémica sobre el ateísmo que modificó no sólo el pensamiento de Fichte, sino también la escena filosófica en Alemania.

Aquí «fe» o «creencia» (Glauben) significa una captación inmediata de la realidad de algo, y se contrapone a la comprensión mediada por conceptos y pruebas o deducción. Lo originario o lo primero en el sistema no puede ser demostrado, sino que su captación es inmediata. «Toda demostración presupone algo absolutamente indemostrable. Aquello de lo que parte la WL no se deja captar ni transmitir por medio de conceptos, sino que únicamente puede ser intuido inmediata o directamente». ${ }^{60}$ Del Yo como primer principio tenemos una intuición intelectual, ${ }^{61}$ por tanto de él no es posible ninguna demostración, sólo una conciencia que Fichte, siguiendo a Jacobi, llama Glauben. El idealismo transcendental parte de esa captación inmediata de la realidad del Yo. ${ }^{62} \mathrm{Si}$ se la quisiera deducir de algún otro elemento, se la haría dependiente y se convertiría la acción del Yo en una ilusión, lo que va en contra del sentimiento de libertad y de la responsabilidad moral, o sea, en contra «de un interés práctico: yo quiero ser autónomo, y por eso me tengo por tal. Pero un tal asentimiento es una $f e$. Por tanto nuestra filosofía parte de una fe, y lo sabe». ${ }^{63}$

La fe en la realidad de la libertad, situada al inicio (alfa), es por otra parte fe también en su fuerza real y en su progresiva realización final en el mundo (omega). «A nuestras representaciones de Dios, moralidad, derecho, etc. les corresponde igualmente una validez objetiva, como a nuestras representaciones del mundo. Ambas se fundan en sentimientos. La diferencia entre ellas reside en que las representaciones del mundo se fundan en un sentimiento de nuestra limitación, las de Dios etc. en un sentimiento de nuestra aspiración. Entre ambas se halla el actuar». ${ }^{64}$ Lo divino no es pues un concepto de la naturaleza o del mundo (de la limitación), sino un concepto moral, porque el pensar teórico, la experiencia objetiva, nunca llega a lo incondicionado, como lo ha demostrado Kant en su Crítica de la razón pura. Sólo en el ámbito moral llegamos a lo originario, que se presenta en la forma de acción libre. En la dialéctica de la Crítica de la razón práctica Kant había hablado además de «una fe racional pura y prácti-

60 «Sobre el fundamento de nuestra fe», GA I/5, 350 Anm., 1. 18-20.

61 Segunda Introducción $\S \S 5$ y 6, GA I/4, 216 ss.

62 Segunda Introducción § 5, GA I/4, 219. SL98, GA I/5, 65. EE § 5, GA I/4, 194-195. Siehe auch ZE § 6, GA I/4, 221.

63 SL98 (= Ética de 1798) §1, GA I/5, 43, 1. 5-11. «Yo soy realmente libre, ese es el primer artículo de fe que no abre el paso al mundo inteligible y nos ofrece en él por primera vez un suelo firme. Esta fe es a la vez el punto de unión entre los dos mundos, y desde él parte nuestro sistema, que también ha de abarcar ambos mundos» (SL98 § 3, GA I/5, 65, 1. 18-21). Véase asimismo Platner-VLM, GA II/4, 326; BM III, GA I/6, 257-259.

64 WLnm-K, GA IV/3, 408, 1. 27-32. 
ca», ${ }^{65}$ no teórica ni pragmática, en Dios y en la inmortalidad del alma como condiciones de posibilidad del bien supremo, es decir, de la realización plena y última de la tarea moral o reino de Dios (omega). La misma acción moral es ya una fe o creencia en la consecución de su meta, la voluntad y la apuesta de que la libertad y la justicia logren imponerse. Fichte había traducido ya en su Reseña del Aenesidemus (1794) esa idea de Kant conforme a su lenguaje: «Aquella unificación en la que el Yo, por medio de su autodeterminación, determina a la vez todo No-Yo (la idea de la divinidad), es la última meta de esa aspiración [del Yo como razón práctica]; una tal aspiración, cuando el Yo inteligente se representa la meta de la misma fuera de él, es una fe (fe en Dios)»r. ${ }^{66}$ Esta fe tiene el mismo grado de certeza que el inmediatamente cierto «Yo soy»; la fe en Dios, o mejor dicho en lo divino, y en el gobierno divino del mundo se mantiene igualmente sin prueba, sin mediaciones. ${ }^{67} \mathrm{~A}$ esta fe pertenecen también «la fe en una inconmensurable perfectibilidad de la humanidad», ${ }^{68}$ la fe en que la moralidad es realizable en el mundo, ${ }^{69}$ que «se da un progreso en el bien [...], que la promoción del fin de la razón es ciertamente posible y que aquel progreso hacia lo mejor sucede necesariamente. Pero esa fe, cuando se la investiga más de cerca, es la fe en Dios y en la inmortalidad», porque esa meta escapa al poder de un ser finito, ${ }^{70}$ como Kant lo expone en la dialéctica de su segunda Crítica.

Ahora bien, al contrario que Kant, el Dios en el que cree Fichte no es una persona, pues para llegar a ser persona se necesita estar en relación recíproca con otras personas, tener un cuerpo, actuar en un mundo, o sea, experimentar reales limitaciones dinámicas, tal y como lo explica Fichte en su Fundamento del derecho natural (1796-7). ${ }^{71}$ Sin finitud ni contraposición no hay distinción ni por tanto conciencia, subjetividad. Por eso Fichte no defiende un teísmo, como Kant, sino que habla de lo divino. ${ }^{72}$ Fichte identifica eso divino con el Yo puro cuando lo diferencia de los yoes empíricos y lo piensa como una fuerza que actúa hacia su plena realización. Cuando vivimos y actuamos y no filosofamos ni poetizamos, consideramos que el mundo es algo independiente de nosotros y «el Yo puro [...] es puesto fuera de nosotros, y se denomina Dios. ¿Cómo lle-

65 AA V, 146, 1. 5-6. Véase también Crítica del Juicio $\S \S 86$ ss.

$66 \mathrm{GA} \mathrm{I} / 2,65,1.19-23$.

67 «Sobre el fundamento de nuestra fe», GA I/5, 348.

68 SL98 § 18, GA I/5, 217, 1. 7-8; véase también p. 248-249.

69 Platner-VLM, GA II/4, 300, 302, 304, 319, 321. BM, GA I/6, 276-277. VLM-1797, GA IV/1, 431. Pero dado que estamos siempre en camino, la moralidad nunca será enteramente realizada (BG (= Destino del sabio), GA I/3, 32).

70 SL98 § 30, GA I/5, 305, 1.12 ss. Véase asimismo Platner-VLM, GA II/4, 297-299.

71 GNR (= Fundamento del derecho natural) $\S \S 1-7$, GA I/3, 329 ss. «Sobre el fundamento de nuestra fe», GA I/5, 355. VS, GA I/6, 51. Platner-VLM, GA II/4, 321-322. BM (=El destino del hombre), GA I/6, 297.

72 Platner-VLM, GA II/4, 282, 1. 5; también 302. 
garíamos a los atributos que adscribimos a Dios y negamos en nosotros, si no los encontráramos en nosotros mismos y únicamente bajo cierto aspecto (en cuanto individuo) los negáramos en nosotros?»». ${ }^{73} \mathrm{La}$ idea de la divinidad es precisamente la de un Yo puro, pura actividad o agilidad, enteramente libre y al que no se le opondría nada, ninguna fuerza contraria que le limitara. ${ }^{74}$

Pero ese ideal como divinidad, o esa divinidad como ideal, se halla en realidad para nosotros, seres finitos, no en el comienzo, sino siempre en el futuro, al final de nuestra tarea. Es una perfección que nosotros, en cuanto hombres e individuos sensibles, incluso nunca podremos alcanzar con plenitud; únicamente la aproximación asintótica e ilimitada hacia ella es nuestro destino moral. ${ }^{75}$ No obstante hemos de aceptar la viabilidad de este fin moral, pues debemos realizarlo, y el mundo obtiene sólo verdadera realidad y sentido cuando es comprendido como «el material hecho sensible de nuestro deber». ${ }^{76}$ Esa plenitud significa la realización completa del Yo puro, de la libertad moral en el mundo, en el NoYo: «Por ejemplo, todos los hombres deben aprender a llevarse bien, debe imperar una paz general, todos deben conocer la verdad, el género humano debe progresar siempre en cultura, la naturaleza ha de ser dispuesta de manera cada vez más adecuada para los fines de la cultura, etc.». ${ }^{77}$ Este objetivo no está en el poder de ningún hombre, pero nos es impuesto categóricamente por la razón práctica, y en consecuencia nuestro ánimo conforme al deber y nuestro actuar moral son a la vez y necesariamente una fe en la posibilidad de que ese fin, a saber, el reino de Dios, el bien supremo, o como se le quiera llamar, será llevado a cabo. ${ }^{78}$ "Aquel que piensa y actúa de manera íntegra, ciertamente la posee [la fe], aunque no sepa una palabra de ella [...]. Actuar bien es la única profesión de fe verdadera» ${ }^{79}$ La perfección moral no es una idea inerte o una mera posibilidad, sino la meta de la fuerza que despliega la realidad pura y originaria del Yo transcendental. Esa realidad-fuerza originaria es lo divino, alfa y omega, que aparece en la conciencia moral como un orden actuante y un ideal a realizar; ${ }^{80}$

73 Carta a Jacobi del 30 de Agosto de 1795, GA III/2, 392, 1. 17-21.

74 «[...] un Yo al que nada se le opusiera, la impensable idea de la divinidad» (GWL § 5, GA I/2, 391-392).

$75 \mathrm{BG}, \mathrm{GA} \mathrm{I} / 3,32$.

76 «Sobre el fundamento de nuestra fe», GA I/5, 352-353. «El mundo presente existe para nosotros sólo por el mandato del deber» (BM, GA I/6, 284, 1. 15-16).

77 Platner-VLM, GA II/4, 297, 1. 9-12 (también 318).

78 Platner-VLM, GA II/4, 297-304.

79 Platner-VLM, GA II/4, 299, 1. 7-8,14. Pero «dejar a Dios lo que uno mismo puede hacer es absolutamente inmoral» (o.c., GA II/4, 304, L. 18-19). «Cumplir con su deber de corazón es el verdadera servicio de Dios y la única verdadera religión» (o.c., GA II/4, 306, 1. 9-10). «La moralidad es el principio de la fe, no a la inversa» (o.c. GA II/4, 306, 1. 26).

80 «Mediante el Yo transcendental es ciertamente hecho D. [Dios], pero aquí ya no se sigue llamando Yo» (Platner-VLM, GA II/4, 303, 1. 4-5). En el § 11 de la Segunda Introducción (1797) explica Fichte la diferencia entre el Yo como intuición intelectual, como princi- 
más no lo podemos determinar sin que quedemos envueltos en contradicciones. ${ }^{81}$ Aquél que duda de ello o no lo vive ni lo siente en él mismo como su propia esencia, el que requiere una prueba teórica o lo busca sólo como garante de su felicidad, ése es un ateo, pues la única verdadera fe es la acción moral misma. ${ }^{82}$ «Ese orden moral vivo y actuante», ese ordo ordinans, ${ }^{83}$ «es ello mismo Dios; no necesitamos ningún otro Dios ni podemos captar ningún otro». ${ }^{84}$ Esa fuerza divina la experimentamos directamente en el actuar y en la conciencia moral; es «lo más cierto que hay, es incluso el fundamento de toda otra certeza». ${ }^{85}$

\section{LA SÍNTESIS DE LOS SERES RACIONALES}

Aunque Fichte identifica lo divino con el Yo puro, usa propiamente el término de Yo puro para referirse al punto inicial del sistema, y el de lo divino para señalar su meta final y la fuerza que conduce hacia esa meta con mano segura, como en Kant. ¿Y qué encontramos al final del sistema? Si nos fijamos en la WLnm, la versión de la Doctrina de la ciencia que Fichte explicó de 1796 a 1799, ámbito en el que se sitúan la Ética de 1798 y el artículo sobre «El fundamento de nuestra fe», vemos que al final del sistema Fichte trata la comunidad de los yoes, el mundo de los hombres o espíritus o seres racionales (Geisterwelt). Por eso Fichte, en la época en la que sufre la polémica sobre el ateísmo, liga lo divino con el mundo de los espíritus, como claramente se ve en la carta que envía a Schelling de mediados de 1801, ya citada: «A la WL no le falta nada en sus principios, pero sí ciertamente en su conclusión; la síntesis suprema no está en efecto realizada, la síntesis del mundo de los espíritus. Cuando me disponía a elaborar esta síntesis gritaron justamente «ateísmo».» ${ }^{86}$ En efecto, como vimos, lo divino no es ningún concepto procedente de la naturaleza, sino el or-

pio, y el Yo como ideal y perfección. En ambos la individualidad o no se ha formado aún o ha desaparecido ya (GA I/4, 265-266).

81 Platner-VLM, GA II/4, 303. «Aquella fe en algo divino que contiene más que ese concepto del orden moral es, en esa medida, invención y superstición, que puede no ser perjudicial, pero que siempre es indigno de un ser racional y sumamente sospechoso» (Aus einem Privatschreiben, GA I/6, 388, 1. 8-11).

82 «Actuar bien con alegría es la verdadera profesión de fe. Cavilar sobre las consecuencias [de la acción] es ateísmo» (Platner-VLM, GA II/4, 320,m 1. 24-25).

83 Aus einem Privatschreiben, GA I/6, 373, 1.1.

84 „Sobre el fundamento de nuestra fe“, GA I/5, 354, 1. 25-26. Dios «es (la cópula lógica) ningún ser [ningún objeto o cosa], sino puro actuar (vida y principio de un orden suprasensible del mundo), de igual manera que yo, inteligencia finita, no soy un ser, sino un puro actuar, un actuar conforme al deber en cuanto miembro de aquel orden suprasensible del mundo» (Verantwortungsschrift, GA I/6, 46-47).

85 «Sobre el fundamento de nuestra fe», GA I/5, 356, 1. 1-2. Véase también AP (Appellation an das Publikum), GA I/5, 430-431.

$86 \mathrm{GA}$ III/5, 45, 10-13. 
den moral del mundo, y en concreto «una relación de los seres morales entre sí»». ${ }^{87}$ En el análisis de esa relación hemos de descubrir por tanto lo divino. Este aparece como el vínculo (Band) de la pluralidad de los yoes, de los hombres, de los espíritus: «El vínculo que une todo el mundo inteligible es Dios. Una tal intuición ha de ser mostrada absolutamente» ${ }^{88}$ anota Fichte en diciembre de 1800 en un manuscrito donde reelaboraba la WLnm en vistas a su publicación, que nunca tuvo lugar. ${ }^{89}$ Él pensaba escribiendo, y estaba buscando aclarar la conciencia de ese vínculo originario dentro de su sistema, aún del primero, el de Jena, a fin de superar la acusación de ateísmo: «Puesto que la imaginación es la facultad de lo infinito, ¿no hay quizás una intuición pura de Dios, con la que yo pueda ayudar de una vez a mi filosofía?»». ${ }^{90}$ Esa pregunta aún se sitúa en el horizonte del primer Fichte. La solución del segundo irá por otro camino.

¿Cómo aparece esa última síntesis o mundo de los seres racionales al final de la WLnm? Tanto el individuo como la comunidad (síntesis de los espíritus) han de ser deducidos desde el Yo puro, desde las acciones del Yo en síntesis con el No-Yo. ${ }^{91}$ Se podría pensar que la $W L n m$ va desde el individuo a la comunidad, puesto que comienza con la intuición intelectual, que posee un fuerte carácter individual: como acto debe realizarlo cada uno, y en cuanto intuición hace relación a la singularidad en oposición a la universalidad propia del concepto. Lo mismo ocurre con otros momentos de la génesis transcendental del Yo en la WLnm, por ejemplo con el sentimiento o con el cuerpo propio, de manera «que el Yo sólo puede ponerse como individuo». ${ }^{92}$ Sin embargo el individuo como tal aparece propiamente junto con la comunidad, y en concreto en el $\S 13$ de la $W L n m$, con el concepto de la voluntad pura. La voluntad pura es colocada en la esfera de la decisión individual, pero de una decisión que sin embargo sólo es posible en el marco de una comunidad de seres racionales. En efecto, la voluntad pura (moral) debe prescribirse a sí misma la limitación, el fin (el deber), es decir, lo que ella quiere, y a la vez también el acto mismo, la acción determinada. Por ser la fuente de esa concretización, ella es la condición suprema de toda conciencia. Esta autolimitación se da a conocer en un sentimiento, como toda limitación, y en concreto en un sentimiento del deber y del no-estar-permitido, a consecuencia de lo cual un sujeto es tomado como individuo. Pero algo determinado sólo puede ser captado como tal en contraposición a algo determinable, o sea, a una esfera en y desde la que es distinguido como siendo esto y no lo otro.

87 Platner-VLM, GA II/4, 282, 1. 8.

88 Neue Bearbeitung der WL, GA II/5, 385, 1. 28-29.

89 De esa WLnm Fichte sólo había publicado en 1797 y 1798 las Introducciones Primera y Segunda, más el Primer capítulo, y no más debido a la escritura de la Ética y la posterior polémica del ateísmo.

90 Neue Bearbeitung der WL, GA II/5, 401, 1. 30-32.

91 Carta a Jacobi del 30 de agosto de 1795, GA III/2, 392.

92 SL98, GA I/5, 199, 1. 8-9. 
«El Yo en cuanto espíritu es algo determinado, su determinable ha de ser igualmente espíritu, una masa de lo puramente espiritual (sit venia verbo, más adelante se mostrará como el reino de los seres racionales, el Yo es una parte determinada de esa masa [...])», él es «razón, y razón determinada. Su determinable es toda razón (seres de mi especie), lo determinado soy yo y, dado que me contrapongo a una esfera de lo racional, yo como individuo».

Además esta autolimitación y autodeterminación morales del individuo es imposible sin la invitación de los otros, es decir, sin la educación, o sea, sin el reconocimiento y el requerimiento de otros seres racionales para la libre acción, que le da a conocer al individuo el contenido positivo del fin de su querer. Esta comunidad de seres racionales es lo determinable a partir del cual el individuo se comprende como tal y puede decidirse a actuar. ${ }^{94}$ En consecuencia, la comunidad, la relación recíproca entre los seres racionales, es una condición de posibilidad del individuo racional, del hombre: «el hombre (y todo ser finito en general) llega a ser hombre únicamente entre hombre». ${ }^{95}$ «Por tanto la razón individual no puede ser explicada a partir de sí misma [...]. Ningún individuo puede explicarse a partir de sí mismo»; ${ }^{96}$ «la razón no es individuo, sino comunidad». ${ }^{97}$ A partir de ahí se desarrolla la última quintuplicidad (síntesis de cinco elementos) deducida de la WLnm. En esa quintuplicidad el primer elemento (1) es la voluntad, el acto de voluntad, cuando el individuo, sobre la base del requerimiento de los otros, se decide a actuar, a hacer esto y no lo otro. En esa acción surgen dos series (podríamos decir dos series de fenómenos), una ideal y otra real; en el mundo de la conciencia reflexiva es inevitable que lo que es uno aparezca en la dualidad. En la serie real (2) o pensar real (el pensar contemplado desde el punto de vista de la causalidad) encontramos el cuerpo propio (der Leib) del individuo como sensibilización de la voluntad y de su causalidad, más el sentimiento de la fuerza de ese cuerpo y la intuición del objeto real que es producido por el actuar del Yo (por ejemplo, de la mesa que estoy fabricando). En la serie ideal (3) o pensar ideal (el considerado desde el punto de vista de la substancia ${ }^{98}$ ) se halla el concepto de fin, gracias al cual el individuo sabe lo que quiere hacer y sabe que es él quien actúa, más el yo empírico, real, sustantivo, o sea, el individuo concreto (Antonio, Pablo, Juan, etc.) que, en cuanto capacidad sensible-espiritual de querer, quiere y actúa. Ambos momentos, el real y el ideal, el objetivo y el subjetivo, aunque la consideración reflexiva de los mismos los ve necesariamente separados, están en sí sintéticamente unidos mediante la rela-

93 WLnm-K, GA IV/3, 445, 1. 2-9.

94 WLnm $\S 16$.

$95 \mathrm{GN} \S 3$, Corollaria, GA I/3, 347.

96 WLnm § 16, GA IV/3, 469, 1. 9-10 y 19.

97 Platner-VLM, GA II/4, 329, 1. 6.

98 En el $\S 4$ de la GWL el punto de vista de la substancia es la visión idealista y el de la causalidad la realista sobre la relación del Yo y del No-Yo. 
ción recíproca del intuir y del pensar, pues cada elemento se encuentra mediatizado por los otros y a su vez mediatiza a los otros, con los que mantiene una unidad orgánica. ${ }^{99}$

Los elementos que hemos visto de ambas series son todos determinados, y en cuanto tales únicamente pueden ser comprendidos sobre el trasfondo de su correspondiente esfera de lo determinable. Lo objetivo de la acción, es decir, el cuerpo propio y el objeto producido, son vistos como parte de la totalidad de una naturaleza, que es su determinable, y en concreto de una naturaleza que se organiza a sí misma (4). Lo espiritual o subjetivo, o sea, el fin y el yo o individuo real, son comprendidos como lo determinado y situado en la comunidad de seres libres, en el mundo de los espíritus (5), que sería su esfera determinable, ${ }^{100}$ puesto que el impulso hacia la autonomía que hay en toda razón es el impulso de la yoidad. ${ }^{101}$ «El yo determinado es un espíritu puro, luego también lo determinable es espíritu, o sea, un mundo de seres racionales fuera de mí, por tanto el surgimiento de mí como individuo es algo genético; yo me engendro como individuo saliendo de un reino de la razón». ${ }^{102}$ En consecuencia todo individuo es una parte determinada y una visión particular del mundo de los espíritus, en él tiene un destino y tarea concretos, un puesto preciso en el orden moral de mundo. Su individualidad es esa concreción de la tarea moral general, del imperativo categórico. En ella consiste el sentido, la verdad y la realidad de su existencia. ${ }^{103}$ Esa limitación particular es impuesta también por la libertad de los otros, ${ }^{104}$ y la WL no puede deducirla ni penetrarla. ${ }^{105}$ Cada uno ha de descubrir lo que ha de hacer desde sí mismo siguiendo su impulso originario y el sentimiento interno de su conciencia. ${ }^{106}$ En la Ética de 1798 Fichte quiere explicar esta tarea y limi-

99 WLnm $\S 17$.

$100 \mathrm{WLnm} \S 18$. «No tenemos una conciencia determinada (individual) sin tener lo determinable (lo universal de la razón finita), y a la inversa. Esta ley es justamente la ley fundamental de la finitud» (carta a Schelling del 31 de mayo - 7 de agosto de 1801, GA III/5, 47, 1. 23-24).

101 SL98 § 18, V, GA I/5, 209-210.

102 WLnm $\S 18$, GA IV/3, 503, 1. 34-37.

103 «Yo no sólo soy moral en general, sino que tengo deberes concretos, determinados por mi individualidad [...] (finitud así determinada, un semejante punto de vista en la cadena del orden moral)» (Platner-VLM, GA II/4, 326, 1. 27-28, 30-31). «La conciencia moral es lo que en cada situación de la vida, cuando le preguntamos, nos dice determinantemente lo que es mi deber en esa situación, es decir, lo que hemos de aportar en ese caso a la promoción de aquel fin de toda razón» (AP, GA I/5, 426, 1. 13-16). Véase también BM III, GA I/6, 261.

104 «No puede ni me está permitido se y devenir todo, porque hay otros que también son libres» (SL98, GA I/5, 205, 1. 14-15).

105 SL98 $§ 18$, GA I/5, 204-205. La WL explica que debe haber un mundo y un mundo determinado en general, porque eso es condición de posibilidad de la conciencia, del Yo, pero no puede deducir qué mundo determinado en concreto habrá, que personas en concreto o animales u objetos existirán. Esa particularización es conocida sólo de manera empírica.

106 SL98, GA I/5, 189 ss. 
tación moral particular de cada individuo desde la idea (protestante y leibniziana) de una predeterminación o predestinación. Todo lo que sucede «tiene que ser primeramente explicable desde algo en nosotros», ${ }^{107}$ conforme lo exige el método transcendental. Por tanto «las acciones libres de los otros deben [...] hallarse en mí originariamente como puntos-límites de mi individualidad», ${ }^{108}$ y la percepción de este influjo está predeterminada en mí. Con ello, según Fichte, no se elimina la libertad, porque no está prefijado cómo voy a reaccionar (y yo soy acción) ni qué otro individuo ejercerá dicho influjo. Todas las acciones libres están predeterminadas desde toda la eternidad, pero no los actores ni el momento en que sucederá, pues el tiempo es una forma pura de la intuición de seres finitos. ${ }^{109}$

De ese modo está pensada la síntesis final de los seres racionales en la WLnm. De Dios aquí no se dice nada. Esa pudo ser una razón de por qué Fichte no quiso publicarla así, una vez desatada la polémica sobre el ateísmo, y de por qué afirmó en su carta a Schelling del 7 de diciembre de 1800 que a su filosofía «le falta aún un sistema transcendental del mundo inteligible». ${ }^{110}$ En la WLnm lo que se nos dice es que el pensamiento del deber presupone un sistema de lo determinable, un reino de seres racionales, una comunidad, que haga posible lo que debo hacer. ${ }^{111}$ Sin embargo hemos de admitir que la completa realización de la unidad sintética racional de esa comunidad espiritual debe ser pensada como una tarea infinita y una meta moral, como ya se afirma en Sobre la dignidad del hombre, un temprano escrito de Fichte de 1794: «Todos los individuos son englobados en la unidad única y grande del espíritu puro ([...] La unidad del espíritu puro es para mí un ideal inalcanzable, un fin último que, sin embargo, nunca se hará efectivo) Esta es la última palabra». ${ }^{12}$ Esta última palabra está ahora sin embargo ligada a la fe en el gobierno divino del mundo, a la fe en un orden moral conseguido, como lo hemos visto en el artículo aludido.

107 SL98, GA I/5, 204, 1. 5-6.

108 SL98, GA I/5, 205, 1. 27-28. Véase asimismo Vorlesung über die Moral, GA IV/1, 112-114.

109 SL98, GA I/5, 207. Ver también Platner-VLM, GA II/4, 329. Lauth afirma (GA IV/2, 11 Anm.), que en esas Platner Vorlesungen (GA II/4, 312-330) Fichte ya defiende una teoría de la relación interpersonal distinta de la WLnm. A mí me parece que es la misma. Esa teoría de la predeterminación es revisada en El destino del hombre (1800), como Fichte le informa a Schelling en carta del 18 de septiembre de 1800 (GA III/4, 314).

110 GA III/4, 406, 21-22. «[...] la síntesis suprema no está en efecto realizada, la síntesis del mundo de los espíritus. Cuando me disponía a elaborar esta síntesis gritaron justamente "ateísmo"» (Carta a Schelling del 31 de mayo / 7 de agosto de 1801, GA III/5, 45, 10-13).

111 WLnm-K, GA IV/3, 442.

$112 \mathrm{GA} \mathrm{I} / 2,89$. 


\section{LA VOLUNTAD INFINITA}

Pronto dejó de satisfacerle a Fichte esta explicación del mundo de los seres racionales, de su síntesis última, como se desprende del esbozo de carta a Reinhold del 18 de septiembre de 1800. Allí afirma que se ha desdicho de ese «apresurado razonamiento» en sus lecciones de 1799 y en el Tercer libro de su Destino del hombre (1800). ${ }^{113}$ En ese Tercer libro afirma que nuestra existencia empírica es un medio para la realización de la razón ${ }^{114}$ y que nuestra voluntad abarca ambos mundos: el suprasensible, en virtud de su decisión, y el mundo sensible mediante su acto. ${ }^{115}$ La voluntad finita es, por una parte, un miembro individual entre otros miembros del mundo racional y, por otra, vive asimismo en un orden sensible con su cuerpo propio y su fin material. «Sólo la razón infinita vive inmediata y exclusivamente en ese orden puramente espiritual». ${ }^{116} \mathrm{La}$ voluntad finita está bajo esta ley del mundo espiritual y es una de sus fuerzas motrices. Como mero acto o mero querer, la voluntad finita se halla enteramente en mi poder, pero que ella se convierta en principio de una serie con consecuencias espirituales, eso depende de una razón pura autónoma. «Ahora bien, una razón autónoma es una voluntad. La ley del mundo suprasensible sería entonces una voluntad»». ${ }^{117}$ Esta ley eterna e inmutable no es proclamada ni por una voluntad finita, ni por la voluntad de todos los seres finitos, sino por una voluntad pura e infinita. ${ }^{118}$ Siguiendo el lenguaje de El Contrato Social de Rousseau, podríamos decir que la ley eterna e inmutable no es proclamada ni por un individuo particular ni por la voluntad de todos (volonté de tous), sino por la voluntad general (volonté général).

Esta voluntad obra únicamente en sí misma, y en ella obran las acciones conforme al deber de las voluntades finitas, porque ella no solamente va por su camino, sino que representa el vínculo espiritual (o la unidad de la síntesis) del mundo racional. En ella y por ella (y no por una especie de predestinación, como se afirmaba en la WLnm) cada voluntad singular y conforme a la ley tiene efectos «en el resto del mundo espiritual, que no es otra cosa que producto de la voluntad infinita». ${ }^{119}$ En consecuencia, las relaciones recíprocas entre los hombres no están dadas ya por la constitución de nuestra individualidad, como se decía en la WLnm, sino que descansan en esta sublime voluntad viva en la que se encuentran y viven todas las voluntades finitas, dado que ella es nuestra fuente primordial, la fuente primordial del mundo espiritual. Todo lo demás es mero

\footnotetext{
$113 \mathrm{GA}$ III/4, 314.

$114 \mathrm{BM}, \mathrm{GA} \mathrm{I} / 6,277$.

$115 \mathrm{BM}, \mathrm{GA} \mathrm{I} / 6,280$.

$116 \mathrm{BM}, \mathrm{GA} \mathrm{I} / 6,284,1.25-26$.

$117 \mathrm{BM}, \mathrm{GA} \mathrm{I} / 6,291,1.32-34$.

$118 \mathrm{BM}, \mathrm{GA} \mathrm{I} / 6,290$.

119 BM, GA I/6, 292, 1. 23-24.
}

Suplemento 19 (2014) de Contrastes. Revista internacional de filosofía 
fenómeno y apariencia. ${ }^{120}$ Esta voluntad es la que me une a ella misma y a los otros seres finitos. La voz de la conciencia es su voz, y traza la frontera de nuestra personalidad, de nuestra individualidad moral, pues «¿qué cosa pudiera limitar a la razón sino la razón misma?». ${ }^{121}$ El conocimiento de la naturaleza surge de las leyes aprióricas del pensar del Yo, y por consiguiente el mundo es dependiente de mí. Pero ¿cómo podría yo saber de una voluntad libre e influir en ella, si ella es enteramente independiente de mí? «El conocimiento que tenemos el uno de otro no fluye directamente de ti a mí; nosotros en cuanto tales estamos aislados por una infranqueable frontera separadora. Únicamente por nuestra fuente espiritual común sabemos el uno del otro; sólo en ella nos conocemos el uno al otro e influimos el uno en el otro». ${ }^{122} \mathrm{La}$ concordancia entre todos nosotros es el resultado de una voluntad eterna e infinita, en nosotros, en nuestros ánimos, ella crea y forma para sí continuamente mediante la llamada del deber el mundo sensible, porque nosotros somos y vivimos en ella y por ella. ${ }^{123}$

¿Compartimos todos un espíritu común, una actividad espiritual y creadora, gracias a la cual nos comunicamos entre nosotros por medio del lenguaje y del cuerpo y podemos ser responsables ante los demás, o existe un espíritu del que obtenemos es actividad espiritual y que nos pone en relación mutua? ¿Existe lo divino o un Dios? Al final de su investigación sobre el mundo espiritual Fichte quiere ahora descubrir una voluntad infinita y autónoma (selbständigen) que, al parecer, no sólo posibilita una unidad transcendental sintética (o un vínculo) entre los espíritus, sino que también nos conduciría a una cierta transcendencia, de la que no se había hablado ni en la WLnm ni en el artículo «Sobre el fundamento de nuestra fe» (excepto en la cita de la poesía de Schiller ${ }^{124}$ ). Ella es una voluntad «que ningún nombre la nombra ni ningún concepto la abarca», ${ }^{125}$ porque ella «no sólo según el grado, sino según su especie se diferencia» de la voluntad finita, ${ }^{126}$ pues ha de ser pensada sin límites ni personalidad, sin conciencia discursiva, y sin embargo providente. De ella sólo conocemos inmediatamente su voz y su requerimiento moral, pues el resto permanece para nosotros

120 BM, GA I/6, 293, 1. 8, 10-11. Algo parecido se decía ya en AP (Appellation an das Publikum), publicado a principios de 1799, pero sin designar a Dios como voluntad: «Nuestra filosofía niega la existencia de un dios sensible y de un servidor de nuestros deseos; pero el Dios suprasensible es para ella todo en todo; es para ella el único que es, y nosotros todos, espíritus racionales, vivimos y nos movemos únicamente en Él» (AP, GA I/5, 440, 1. 24-27).

$121 \mathrm{BM}, \mathrm{GA} \mathrm{I} / 6,293,1.22-23$.

122 BM, GA I/6, 294, 1. 33-37. «Por tanto, incluso lo que en el mundo nosotros llamamos mal moral es consecuencia del mal uso de la libertad, y es únicamente por Él» (299, 1. 12-13).

123 Dios «no se encuentra lejos de cada uno de nosotros, pues en Él vivimos, nos movemos y existimos» (Hechos de los Apóstoles 17, 27-28).

124 «Sobre el fundamento de nuestra fe», GA I/5, 357, 1. 25.

$125 \mathrm{BM}, \mathrm{GA} \mathrm{I} / 6,296,1.28$.

$126 \mathrm{BM}, \mathrm{GA} \mathrm{I} / 6,297,1.17-18$.

Suplemento 19 (2014) de Contrastes. Revista internacional de filosofía 
incomprensible. ${ }^{127}$ Por tanto hemos dado un paso más allá en el ámbito de lo divino, y en concreto con inspiración religiosa: «únicamente el ojo religioso penetra en el reino de la verdadera belleza». ${ }^{28}$ Mientras que en el período de Jena la experiencia moral era para Fichte la suprema, como en Kant, desde ahora la inspiración religiosa será la dominante.

La serie ideal del mundo espiritual que aparecía en la WLnm nos ha conducido a una voluntad infinita y autónoma, divina, que sería lo más real y lo que es en sí, ${ }^{129}$ mientras que la serie de la naturaleza, una serie que antes se denominaba real, se va transformando más bien en una sombra, en algo meramente ideal, ${ }^{130}$ de tal manera que el No-Yo, que en la Fundamentación de toda la Doctrina de la ciencia (1794-5) funcionaba como segundo principio del sistema, porque era en parte incondicionado, y que estaba aún presente en la WLnm, se encuentra en claro declive. El No-Yo será disuelto en el saber absoluto o manifestación de Dios como un momento de su desarrollo, ya que ese fenómeno o manifestación (o saber, luz exterior, ver, imagen, esquema) es para nosotros el verda-

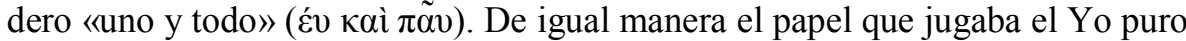
colocado al inicio del sistema como realidad originaria será recogido por esa voluntad pura y su manifestación o fenómeno, el cual al final del sistema es descubierto como la fuente originaria y el vínculo de los yoes y de su mundo compartido. En una de sus últimas carta a Schelling, a mediados de 1801, Fichte afirmaba: La conciencia individual determinada (C) asumida en la conciencia absoluta (A) «proporciona un sistema del mundo de los espíritus (el B anterior) $\mathrm{y}$ un fundamento real incomprensible de la separación de los individuos, y un vínculo ideal de todos $=$ Dios. Esto es lo que llamo el mundo inteligible. Esa última síntesis es la suprema. $\mathrm{Si}$ a aquello que para esa mirada permanece aún impenetrable se lo quiere llama «ser», y en concreto lo Absoluto, entonces Dios es el ser puro; pero ese ser es en sí no algo así como algo comprimido, sino enteramente una agilidad, pura penetración, luz, no la luz que reflejan los cuerpos. Esto último es sólo para la razón finita, por tanto es un ser sólo para ésta, no en sí»». ${ }^{131}$

127 BM, GA I/6, 297-299, 305. Pienso que esa transcendencia dificulta la comprensión de la relación y comunidad entre los hombres, e intenta, como los alquimistas, explicar lo oscuro por lo más oscuro, porque de esa voluntad infinita sólo conocemos propiamente la "voz" en la ley moral, y el resto permanece incomprensible.

128 BM, GA I/6, 306, 1. 11-12.

129 «Sólo la razón es, la razón infinita en sí, y la finita es en ella y por ella» (BM, GA I/6, 296, 1. 11-12).

130 Esta es la única visión que le corresponde al hombre, «en la cual todo lo sensible se le transforma en nada, en un mero reflejo de lo suprasensible, lo único consistente, en los ojos mortales» (BM, GA I/6, 300, 1. 15-17).

131 Carta de Schelling del 31 de mayo - 7 de agosto de 1801, GA III/5, 48, 1. 11-19. «Ser» tiene en Fichte esos dos significados: el de mera cosa u objeto, y el de lo más real. 
En su siguiente comunicación del 3 de octubre de 1801, Schelling le hace la observación de que ésa es una nueva idea que no había aparecido nunca antes en la WL: «Lo que ahora es su síntesis suprema, eso era extraño al menos para sus exposiciones anteriores, pues según ellas Dios era el mismo orden moral del mundo (sin duda lo que Usted ahora llama la separación real de los individuos y la unidad ideal de todos). Pero ahora, si he comprendido bien, no es ese el caso, y eso modifica de manera considerable todo el asunto de su filosofía». ${ }^{132}$ Más aún, si ese ser o agilidad no sólo es la última síntesis sino también la suprema, entonces «ha de ser infaliblemente a la vez lo primero del que se ha partir» ${ }^{133}$ para deducir todo el sistema. Esa propuesta indica el cambio que se opera en Fichte. En un primer momento y en virtud de la polémica sobre el ateísmo, la ley pura y ordenante es sustituida por la voluntad autónoma de Dios en vistas a explicar la relación recíproca de los seres racionales y su esencial unidad; esa voluntad divina se pone en primer plano como fuerza y fuente originaria, como fundamento real e ideal, como la nueva cara de lo totalmente incondicionado. Este paso representa ya la primera señal del nuevo horizonte en el pensamiento fichteano, de su nuevo Absoluto, en el cual el Yo y su libertad son rebajados a algo deducido, y al final comprendidos como un reflejo o imagen del fenómeno o aparición del Absoluto, de un Dios supra-personal. El segundo paso se presenta pronto y en la forma de un vuelco: el Dios que aparecía al final del sistema, como ocurría también en Kant, y en concreto al final de la serie ideal del mundo de los seres racionales, es colocado en el primer lugar y comprendido como lo verdaderamente real. La WL01/02 comienza su discurso con el Absoluto y su fenómeno o manifestación, comprende ese fenómeno de Dios como saber e imagen del Absoluto, y deduce de él todo el sistema: «El saber no es el Absoluto, pero él en cuanto saber es absoluto». ${ }^{134}$

\section{UN ENSAYO DE INTERPRETACIÓN INTERNA}

Para interpretar esta evolución de Fichte, podríamos echar mano de su teoría de las cinco visiones del mundo (Weltansichten), que expone en su período berlinés. ${ }^{135}$ De esa manera cabría entender esa teoría como una interpretación interna de las fases por las que habría pasado su propio pensamiento, como si dicha teoría fuera una mirada retrospectiva hacia sí mismo, una interpretación de la propia experiencia y camino filosóficos de Fichte.

El joven Fichte, el anterior a su encuentro con la filosofia kantiana en agosto de 1790 , era determinista, y por tanto estaría más cercano a la primera manera

$132 \mathrm{GA}$ III/5, 83, 1. 11-15.

133 GA III/5, 82, 1. 7-8.

$134 \mathrm{GA}$ II/6, 153, 1. 2.

135 Vease también WL042, Lección XXVIII (GA II/8, 417 und 419). ASL, Lección quinta (GA I/9, 103-114). 
de entender el mundo, ciertamente no porque él considerara a los entes sensibles como lo supremo, pero sí porque ponía al ser objetivo por delante de la acción libre, a lo fijo por encima de la agilidad, como hacían los «dogmáticos», según su modo de hablar.

La segunda manera de ver el mundo es pensar que lo supremo se encuentra en una ley de la libertad que ordena el mundo existente «como una ley del orden y del derecho igualitario, en un sistema de seres racionales, [...] Una ley, y en concreto una ley que ordena e iguala, para la libertad de muchos, esa es para esta visión lo propiamente real y lo que existe para sí mismo». ${ }^{136}$ En ese ordo ordinans del mundo de los seres racionales en cuanto ley moral actuante consistía para Fichte lo divino justamente hasta la polémica sobre el ateísmo. A pesar de su afirmación en el libro Exhortación a la vida bienaventurada (1806) de que él no había considerado «nunca a esa visión del mundo [...] como la suprema», ${ }^{137}$ de hecho él mismo colocó su propia Fundamentación del derecho natural y su Ética de Jena, o sea, su pensamiento en el tiempo de la WLnm, al mismo nivel que la ética y el derecho de la conciencia común y de Kant, a saber, en este segundo punto de vista, el de la moral inferior, ${ }^{138}$ mientras que con su Ética de 1812 quiere ilustrar expresamente la ética superior. ${ }^{139}$

Justo después de la polémica del ateísmo y debido a la acusación de nihilismo vertida por Jacobi, Fichte se ve impelido a pasar del punto de vista de la legalidad al de la moralidad superior. Esta moralidad superior nos introduce en la tercera visión del mundo. Para ambas moralidades, la inferior y la superior, lo supremo es la ley, pero en la inferior la ley sólo tiene una función ordenadora (legalidad), mientras que en la moral superior posee una función creadora: la ley es considerada como fuente creadora de nueva vida, una vida que debe servir «como imagen y reproducción creadora, como revelación del ser interno divino». ${ }^{140}$ Lo supremo, «lo verdaderamente real y autónomo es para ella [para la moralidad superior] lo santo, lo bueno, lo bello». ${ }^{141}$ Ella es por consiguiente una moralidad de inspiración religiosa. Eso lo podemos encontrar en la voluntad infinita, autónoma y divina que hemos visto en el Tercer libro de El destino del hombre.

136 ASL, GA I/9, 107, 1. 15-19.

137 ASL, GA I/9, 108, 1. 10-11.

138 ASL, GA I/9, 107-108.

139 SL12, GA II/13, 324, 328-329. «El principio fundamental de la Ética [de 1812] puede ser captado también así: el yo tienen que aparecer a sí, únicamente como fenómeno, pues no debe ser su vida, sino la vida de algo extraño y otro, del concepto [de Dios]. Nunca una voluntad o vida propias, sino únicamente el fenómeno, la visibilidad del concepto, la cual se desprende de aquel, y el Yo tiene sólo la contemplación pasiva de su surgimiento y de su ser» (GA II/13, 339, 1. 30-35).

140 ASL, GA I/9, 109, 1. 29-30.

141 AzL, GA I/9, 109, 1. 31-32. 
En esta tercera visión del mundo se encuentra ya, según el segundo Fichte, el primer y verdadero barrunto de lo verdadero, pero su conocimiento se alcanza en el cuarto punto de vista, el de la religión, y de manera plena y completa en el quinto, el de la filosofía, el de la WL. En estas dos últimas visiones del mundo lo divino es vivido como vida y amor y entendido como el ser absoluto, que es vida absoluta interior y escondida en sí, pero que proyecta una vida o luz o saber exterior en el que se manifiesta y que somos nosotros y nuestro mundo. Este ya no es nuestro producto o producto del Yo, sino manifestación de Dios. A esa manifestación de Dios nos hemos de entregar (hingeben), porque «sólo Dios es, y fuera de él no hay nada». ${ }^{142}$ Este es el nuevo horizonte del pensar que inicia su andadura con la WL01/02. La voluntad infinita y autónoma de El destino del hombre es aún luz y penetrabilidad, ${ }^{143}$ para el cual Fichte, como hemos visto, busca incluso una intuición adecuada ${ }^{144}$ (tercera visión del mundo), al igual que el Yo absoluto de la WL en Jena se ponía mediante una intuición intelectual. Pero en las Doctrinas de la Ciencia del segundo período, el Absoluto o lo absolutamente real es empujado más allá, por detrás de su fenómeno, de nuestro mundo y del saber, oculto en lo incomprensible (cuarta y quita visión del mundo): «Todo en el Uno, todo Uno. En efecto, a saber, en el único fenómeno. En Él [Dios] vivimos, nos movemos y somos: ciertamente, en su fenómeno, nunca en su ser absoluto». 145

JACINTO RIVERA DE ROSALES es catedrático de filosofía en la UNED, profesor de historia de la filosofía moderna. Actualmente es decano de la Facultad de Filosofía de la UNED y presidente de la Sociedad Fichteana Internacional.

Linea de investigación:

Kant, idealismo alemán, filosofía moderna, hermanéutica, ontología, ética, estética.

\section{Publicaciones recientes:}

- «Heidegger and Kant's Refutation of Idealism», en Objectivity after Kant. Its Meaning, its Limitations, its Fateful Omissions, Olms, Hildesheim, 2013, pp. 249-278.

- «Versuch, den Begriff des eigenen Körpers in die Kritik der reinen Vernunft einzuführen», en el libro Das Leben der Vernunft. Beiträge zur Philosophie Kants, Walter de Gruyter, Berlín, 2013, pp. 109-130.

- «Ortega und Fichte - Ein Nationen aufbauender Sozialismus», Fichte-Studien, 38 (2013), pp. 179-200.

Dirección electrónica: jrivera@fsof.uned.es

142 ASL, GA I/9, 110, 1. 21.

143 Carta a Schelling del 31 de mayo - 7 de agosto de 1801, GA III/5, 48.

144 Neue Bearbeitung der WL, GA II/5, 385 y 401.

145 WL12, GA II/13, 60, 1. 23-25. 